\title{
HLA-DRB1 shared epitope genotyping using the revised classification and its association with circulating autoantibodies, acute phase reactants, cytokines and clinical indices of disease activity in a cohort of South African rheumatoid arthritis patients
}

Pieter WA Meyer ${ }^{1 *}$, Bridget Hodkinson ${ }^{2}$, Mahmood Ally ${ }^{3}$, Eustasius Musenge ${ }^{4}$, Ahmed A Wadee ${ }^{5}$, Heidi Fickl', Mohammed Tikly ${ }^{2}$ and Ronald Anderson ${ }^{1}$

\begin{abstract}
Introduction: The revised shared epitope (SE) concept in rheumatoid arthritis (RA) is based on the presence (S) or absence $(X)$ of the SE RAA amino acid motif at positions 72 to 74 of the third hypervariable region of the various human leucocyte antigen (HLA)-DRB1 alleles. The purpose of this study was to investigate SE subtypes on the basis of the American College of Rheumatology 1987 revised criteria for the classification of RA in a cohort of South African RA patients $(n=143)$ and their association with clinical and circulating biomarkers of disease activity (autoantibodies, acute phase reactants and cytokines).
\end{abstract}

Methods: Genomic DNA was analysed using high-resolution recombinant sequence-specific oligonucleotide PCR typing of the HLA-DRB1 allele. Subtypes of the SE were classified according to the amino acids at positions 72 to 74 for the RAA sequence, and further sub-divided according to the amino acids at positions 70 and 71 , which either contribute to (S2, S3P), or negate (S1, S3D) RA susceptibility. Disease activity was assessed on the basis of (1) Disease Activity Score in 28 joints using C-reactive protein (CRP), (2) rheumatoid factor (RF), (3) CRP and (4) serum amyloid A by nephelometry, anticyclic citrullinated peptide antibodies (aCCP) by an immunofluorometric procedure, and cytokines by multiplex bead array technology.

Results: Of the 143 RA patients, 81 (57\%) were homozygous (SS) and 50 (35\%) were heterozygous (SX) for the SE alleles with significant overexpression of S2 and S3P (respective odds ratios (ORs) 5.3 and 5.8; $P<0.0001$ ), and 12 (8\%) were classified as no SE allele (XX). Both the SS and SX groups showed a strong association with aCCP positivity $(\mathrm{OR}=10.2$ and $P=0.0010, \mathrm{OR}=9.2$ and $P=0.0028$, respectively) relative to the $X X$ group. Clinical scores and concentrations of the other biomarkers of disease activity (RF, CRP and T helper cell type 1 (Th1), Th2, macrophage and fibroblast cytokines) were also generally higher in the SS group than in the SX and XX groups.

Conclusions: RA susceptibility alleles investigated according to revised criteria for the classification of RA were significantly increased in South African RA patients and strongly associated with aCCP in particular as well as with circulating cytokines and disease severity.

\footnotetext{
* Correspondence: pieter.meyer@nhls.ac.za

${ }^{1}$ Medical Research Council Unit for Inflammation and Immunity, Department

of Immunology, Faculty of Health Sciences, University of Pretoria, and

Tshwane Academic Division of the National Health Laboratory Service,

Bophelo Road, Pretoria, 0001, South Africa

Full list of author information is available at the end of the article
} 
Keywords: anticyclic citrullinated peptide antibodies, C-reactive protein, fibroblast cytokines, macrophage cytokines, rheumatoid factor, serum amyloid A, Th1/Th2 cytokines

\section{Introduction}

Rheumatoid arthritis (RA) is a debilitating autoimmune disease that has no clearly defined aetiology, although there is a definite genetic predisposition and associated risk factors [1]. The shared epitope (SE) concept in relation to genetic predisposition was first described in 1986 and has evolved from the classic HLA-DRB1*01, HLADRB1*04 and HLA-DRB1*10 associations [2-4] to the identification of the RAA amino acid motif at positions 72 to 74 of the third hypervariable region of the different human leucocyte antigen (HLA)-DRB1 chains as the definitive SE [3-5]. This concept has been extended by Gao et al. [6] to include the amino acid residues at positions 71 and 76 and, recently, to a new classification which incorporates the modulatory activities of the amino acids at positions 70 and 71 in addition to the RAA motif at positions 72 to 74 [6-8].

Although the primary triggering autoantigens in RA have not been described to date, it is noteworthy that associations between the various HLA-DRB1 SE subtypes with disease susceptibility and/or severity and the presence of circulating anticitrullinated peptide antibodies have been described [9-18]. In addition, HLA-DRB1 SE genotyping and measurement of anticyclic citrullinated peptide antibodies (aCCP) and, to a lesser extent, rheumatoid factor (RF) have the potential to predict future development of RA [10,14,17,19-21]. Taken together, these associations between HLA-DRB1 SE genotype, aCCP and disease susceptibility and/or severity appear to be compatible with the presentation of citrullinated autoantigens by HLA-DRB1 SE subtypes as an immunopathogenic mechanism in RA.

While lacking diagnostic specificity, the measurement of circulating cytokines and chemokines and acute phase reactants, combined with the detection of aCCP and RF, has the potential to predict the time until onset of clinical disease [22,23] as well as disease severity [24-27]. Nonetheless, in relatively few studies have researchers undertaken a composite analysis of SE genotyping and measurement of circulating aCCP, cytokines, chemokines and acute phase reactants as a strategy not only to identify interactions between these alleles and biomarkers but also to establish which combinations of these are most strongly associated with disease severity. These issues were addressed in the current study of a cohort of predominantly African patients with RA of two years' duration or less. To our knowledge, this is the first study to measure the frequency of the various SE subtypes according to the du Montcel classification system [7] in this patient population.

\section{Materials and methods}

Following approval by the Research Ethics Committees of the Faculties of Health Sciences of the University of Pretoria and University of the Witwatersrand, 143 patients who presented to the rheumatology clinics of two tertiary hospitals in the Gauteng Province of South Africa (Chris Hani Baragwanath Hospital, Soweto, and Steve Biko Academic Hospital, Pretoria) were recruited to participate in the study. Prior informed consent was obtained from all participants, all of whom met the 1987 American College of Rheumatology criteria for RA [28]. All of the patients were disease-modifying antirheumatic drug (DMARD)-naive and HIV-seronegative and had RA symptoms of two years' duration or less. The Disease Activity Score in 28 joints (DAS28) on the basis of CRP level (DAS28-CRP) was used to assess disease activity upon presentation $[29,30]$. "Erosive disease" was defined as the presence of marginal joint erosions on standard X-rays of the hands and feet. These clinical assessments were performed by two experienced rheumatologists (BH and MA). Demographic data for this cohort are shown in Table 1.

\section{Autoantibodies and acute phase reactants}

Venous blood $(30 \mathrm{ml})$ was collected in commercial sample test tubes containing a gel separator. The blood samples were kept at room temperature to clot and then spun at 3,000 rpm for 10 minutes), followed by collection of the serum, aliquoting and storage at $-20^{\circ} \mathrm{C}$ until needed for analysis.

RF (composite immunoglobulin M (IgM), IgG and IgA), CRP and serum amyloid A (SAA) were assayed by

Table 1 Demographic, laboratory and clinical data for the RA patient group $(n=143)$

\begin{tabular}{llll}
\hline Parameters & Data & Median [IQR] & Range \\
\hline Age (years) & $48 \pm 12$ & $48[41$ to 56$]$ & 20 to 75 \\
Females, $n(\%)$ & $118(82.5 \%)$ & & \\
Blacks, $n(\%)$ & $124(86.7 \%)$ & & \\
DAS28-CRP & $5.6 \pm 1.3$ & $5.7[4.8$ to 6.7$]$ & 2.3 to 8.7 \\
Disease duration (months) & $12 \pm 7$ & $10[6$ to 18$]$ & 0 to 25 \\
Larsen radiographic scores & $23 \pm 14$ & $19[14$ to 28$]$ & 1 to 66 \\
RF $(I U / m l)$ & $490 \pm 795$ & $168[38$ to 595$]$ & 4 to 5,350 \\
aCCP $(\mathrm{U} / \mathrm{ml})$ & $669 \pm 636$ & $492[85$ to 1,099$]$ & 2 to 2,527 \\
CRP $(\mu \mathrm{g} / \mathrm{L})$ & $24 \pm 32$ & $14[5$ to 32$]$ & 0 to 198 \\
SAA $(\mu \mathrm{g} / \mathrm{ml})$ & $62 \pm 123$ & $14[5$ to 65$]$ & 1 to 882 \\
\hline
\end{tabular}

$\mathrm{aCCP}=$ anticyclic citrullinated peptide antibodies; $\mathrm{CRP}=\mathrm{C}$-reactive protein; DAS28 = Disease Activity Score in 28 joints; RF = rheumatoid factor; SAA = serum amyloid $A$. Data are means $\pm S D, n(\%)$, medians [25th to 75 th IQR] or raw data as indicated. 
nephelometry (BN ProSpec System; Siemens Healthcare Diagnostics, Deerfield, IL, USA). As per the manufacturer's supplier controls, RF, CRP and SAA results were considered positive when their individual concentrations exceeded $11 \mathrm{IU} / \mathrm{ml}, 5 \mu \mathrm{g} / \mathrm{ml}$ and $6.8 \mu \mathrm{g} / \mathrm{ml}$, respectively. $\mathrm{aCCP}$ were measured using a second-generation immunofluorometric procedure using the ImmunoCAP Phadia 250 assay system with reagents and controls provided by the manufacturer (Phadia AB, Uppsala, Sweden). A concentration greater than $10 \mathrm{U} / \mathrm{ml}$ was deemed positive.

\section{Serum cytokines, chemokines and growth factors}

Serum cytokines, chemokines and growth factors were measured using the Bio-Plex multiplex suspension array system with xMAP technology (Bio-Rad Laboratories, Hercules, CA, USA), which enables simultaneous detection and quantitation of multiple different analytes in a single sample. The system uses an array of microspheres in liquid suspension that are conjugated with a $\mathrm{mAb}$ specific for a target protein. A wide range of standards ( 0.38 to $91,756.00 \mathrm{pg} / \mathrm{ml}$ ) was used to enable quantitation of the individual cytokines by using a Bio-Plex array reader (Bio-Rad Laboratories) with a dual laser detector and real-time digital signal processing. The following analytes were measured: IL-1 $\beta$, IL-1Ra, IL-2, IL4, IL-6, IL-7, IL-8, IL-10, IL-12, IL-17, IFN- $\gamma$, TNF, granulocyte colony-stimulating factor (G-CSF), granulocyte macrophage colony-stimulating factor (GM-CSF), chemokine (C-C motif) ligand 2 (CCL2), CCL4 and vascular endothelial growth factor (VEGF). The upper limits of normal for these analytes were calculated as the mean $+2 \mathrm{SD}$ for 10 healthy control subjects (five female and five male, average age $44.4 \pm 15.0$ years, age range 26 to 65 years).

\section{Typing of human leucocyte antigen-DRB1 alleles}

Genomic DNA was obtained by using the Maxwell 16 System with the Maxwell 16 Blood DNA Purification Kit (Promega, Madison, WI, USA) to extract DNA from whole blood, which was collected in ethylenediaminetetraacetic acid (EDTA) sample tubes. The patients' HLADRB1 alleles were determined by using a DNA-based high-resolution typing method, the LABType HD Class II DRB1 Typing Test (One Lambda Inc, Canoga Park, CA, USA), with reverse sequence-specific oligonucleotide probes and Luminex technology. The target DNA (HLA-DRB1 gene) was amplified by PCR using groupspecific primers biotinylated for detection with streptavidin R-phycoerythrin conjugate. The PCR product was then denatured and hybridised to complementary DNA probes conjugated to fluorophores. Bound DNA was detected on the Luminex system, and software (HLA Fusion\&\#8482 Software Version 2.0, One Lambda,
Inc.,21001 Kittridge Street, Canoga Park, CA, USA)was used to map the reaction patterns to those associated with published $H L A$ gene sequences and assign the represented HLA-DRB1 alleles. HLA alleles were assigned according to the RAA amino acid sequence at positions 72-74 as SE (S) and non-SE (X), and the S group was further subdivided according to amino acid groups at positions 70 and 71 as described by du Montcel et al. [7] (see Table 2). The International Immunogenetics Information System database [31,32] and the Allele"Frequencies in Worldwide Populations Net Database [33] were used to establish regional and ethnicitymatched HLA-DRB1 frequencies in sub-Saharan Africa. The non-SE patients with the no SE allele (XX) genotype $(n=12)$ were used as controls in the calculation of contingency tables.

\section{Statistical methods}

Descriptive and inferential statistics techniques were used in the analyses. Tests for association of contingency tables were performed using either the two-tailed Fisher's exact test or the $\chi^{2}$ test with the Yates correction. One-way analysis of variance (ANOVA) was performed using the Kruskal-Wallis test for nonparametric data for more than two groups, or the Mann-Whitney $U$ test when two groups were compared. Logistic regression was used for binary outcome variables, and the OR and corresponding 95\% confidence interval were reported. $P<0.05$ was considered statistically significant. The analyses were done using Stata software (Stata Corp, College Station, TX, USA).

\section{Results}

\section{Human leucocyte antigen-DRB1 incidence}

All of the "classical" RA-associated HLA-DRB1*01, HLA-DRB1*04 and HLA-DRB1*10 alleles showed statistically significant ORs, with HLA-DRB1*04 the most prominent (Table 3), underscoring the significance of the HLA-DRB1 SE previously reported in the African population [34-38]. The HLA-DRB1 alleles were categorized according to the new classification as being homozygous for the SE allele (SS), heterozygous for the SE allele (SX) or XX. The majority (92\%) of the patients had at least one allele associated with the amino acid motif. More than half $(57 \%)$ of the patients typed were homozygous (SS), 35\% were heterozygous (SX) and only $8 \%$ had no associated HLA-DRB1 allele (XX). The SS, SX and XX allele distribution among the African subgroup of the cohort $(n=124)$ was $58 \%(n=72), 35 \%(n$ $=43)$ and $7 \%(n=9)$, respectively. The other South African population groups (Caucasian, Asian and mixed ancestry) were not meaningfully represented, however.

Classification of RA-associated HLA-DRB1 alleles according to the du Montcel et al. classification system 
Table 2 Shared epitope classification according to amino acid sequence at positions 70-74

\begin{tabular}{|c|c|c|}
\hline Allele classification & Amino acid sequence positions 70 to 74 & HLA-DRB1 alleles \\
\hline \multirow[t]{2}{*}{ S1 } & D-E-RAA & ${ }^{*} 01: 03,{ }^{*} 04: 02,{ }^{*} 11: 02-: 03,{ }^{*} 13: 01-: 02,{ }^{*} 13: 04, * 13: 36,{ }^{*} 13: 40$ \\
\hline & Q-A-RAA & ${ }^{*} 15$ \\
\hline \multirow[t]{2}{*}{ S2 } & Q-K-RAA & ${ }^{*} 04: 01,{ }^{*} 04: 09, * 04: 13,{ }^{*} 04: 35,{ }^{*} 04: 66$ \\
\hline & D-K-RAA & ${ }^{*} 13: 03$ \\
\hline S3D & D-R-RAA & ${ }^{*} 11: 01,{ }^{*} 11: 04, * 11: 27,{ }^{*} 12,{ }^{*} 13: 05-: 06,{ }^{*} 13: 25, * 14: 22, * 16$ \\
\hline \multirow[t]{2}{*}{ S3P } & Q-R-RAA & ${ }^{*} 01: 01-: 02,{ }^{*} 04: 04-: 05,{ }^{*} 04: 08,{ }^{*} 04: 10$ \\
\hline & R-R-RAA & ${ }^{*} 10: 01$ \\
\hline \multirow[t]{5}{*}{$x$} & Q-K-RGR & ${ }^{*} 03$ \\
\hline & Q-R-RAE & ${ }^{*} 04: 03,{ }^{*} 04: 07,{ }^{*} 04: 11$ \\
\hline & D-R-RGQ & ${ }^{*} 07$ \\
\hline & D-R-RAL & *08 \\
\hline & R-R-RAE & ${ }^{*} 09: 01,{ }^{*} 14: 01,{ }^{*} 14: 04$ \\
\hline
\end{tabular}

$\mathrm{HLA}=$ human leucocyte antigen. Data in right column from Gao et al. [6].

[7] revealed that S2 and S3P had significantly higher allele frequencies than those found in the general subSaharan population [32,33]. S3D and the non-epitopeassociated alleles $(\mathrm{X})$ were not significantly different in the RA groups compared to the general sub-Saharan population. As shown in Table 4, S1 was significantly undertransmitted in our population.

\section{Relationship of shared epitope classification and autoantibodies}

Analysis (by one-way ANOVA and Mann-Whitney $U$ test) of the median values of autoantibodies revealed that they were generally higher in the SS group than in the SX group. Significant associations were noted for aCCP (SS vs SX vs XX; $P=0.0298$ ) and for RF (SS vs $\mathrm{XX}, P=0.0129$; SX vs $\mathrm{XX}, P=0.0273$ ).

As $X$ alleles have been shown to be undertransmitted in the RA cohort (that is, noncarriers of risk alleles) (see Table 4), they were used as the control group within the RA cohort to determine the possible associations of the HLA-DRB1 genotype with RA-associated autoantibodies by comparing the total positive and negative results for the RA-associated antibodies (RF and $\mathrm{aCCP}$ ) in the risk groups with those for the control group (XX). As shown in Table 5, both RF and aCCP seropositivity were significantly higher in both the SS and SX groups of the total cohort in comparison with the XX control group. The data are as follows: RF (SS group vs XX control group: $\mathrm{OR}=7.0, P=0.0059$, and $\mathrm{SX}$ group vs $\mathrm{XX}$ control group: $\mathrm{OR}=6.3, P=0.0126$ ) and aCCP (SS group vs XX control group: $\mathrm{OR}=10.2, P=0.0010$, and $\mathrm{SX}$ group vs XX control group: $\mathrm{OR}=9.2, P=0.0028$ ).

The SS and SX groups of the African patients showed a statistically significant predisposition to aCCP seropositivity compared with the XX group (SS group vs XX control group: $\mathrm{OR}=7.01, P=0.0121$; $\mathrm{SX}$ group vs $\mathrm{XX}$ control group: $\mathrm{OR}=6.4, P=0.0223$ ), and $\mathrm{RF}$ was also more prevalent in the SS and SX groups compared to the XX control group, although the difference was not significant (Table 5). Stratifying the patients according to du Montcel et al.'s allele classification [7] as SS, SX or XX therefore seems to strengthen the genetic association with the presence of aCCP, an observation which is in agreement with the findings of Huizinga et al. [14] and Klareskog et al. [39].

Further analysis was undertaken to probe the associations with the amino acids at positions 70 and 71 (S1, S2, S3D and S3P) with aCCP seropositivity by comparing noncarriers with the carrier allele groups. As shown in Table 6, this analysis revealed significantly higher ORs in the case of the S2 and S3P allele groups and weak, albeit significant, associations with the S1, S3D and $\mathrm{X}$ allele groups. RF seropositivity was weakly associated with all allele groups.

The association between SE genotype and aCCP or RF seropositivity was further probed by categorising patients into high-risk or low-risk allele groups according to the du Montcel classification system [7] with the

Table 3 Human leucocyte antigen-DRB1 rheumatoid arthritis-associated alleles, odds ratios and confidence intervals in the rheumatoid arthritis patient cohort

\begin{tabular}{lllll}
\hline Risk allele & RA patients, $\boldsymbol{n}(\boldsymbol{\%})(\boldsymbol{n}=\mathbf{1 4 3})$ & Controls*, $\boldsymbol{n}(\boldsymbol{\%})(\boldsymbol{n}=\mathbf{1 , 1 0 4 )}$ & OR $(\mathbf{9 5 \%} \mathrm{Cl})$ & $\boldsymbol{P}$ value \\
\hline HLA-DRB1 $^{*} 01$ & $26(18.2)$ & $93(8.4)$ & $2.4(1.5$ to 3.9$)$ & 0.0007 \\
HLA-DRB1 $^{* 04}$ & $61(42.7)$ & $41(3.7)$ & $19.3(12.2$ to 30.4$)$ & $<0.0001$ \\
HLA-DRB1 $^{*} 10$ & $10(7.0)$ & $36(3.3)$ & $2.2(1.0$ to 4.6$)$ & 0.0338 \\
\hline
\end{tabular}

$\mathrm{HLA}=$ human leucocyte antigen; $\mathrm{OR}=$ odds ratio; $\mathrm{RA}=$ rheumatoid arthritis. ${ }^{*}$ Data from Robinson and colleagues $[31,32]$. 
Table 4 Comparison of allele carrier frequencies in RA cases and controls in accordance with the du Montcel classification

\begin{tabular}{lccccc}
\hline Allele & RA patients, $\boldsymbol{n}(\boldsymbol{\%})(\boldsymbol{n}=\mathbf{1 4 3})$ & Controls $^{*}, \boldsymbol{n}(\boldsymbol{\%})(\boldsymbol{n}=\mathbf{1 , 1 0 4 )}$ & $\mathbf{X}^{\mathbf{2}}$ test & OR (95\% Cl) & $\boldsymbol{P}$ value \\
\hline S1 & $55(39)$ & $853(77)$ & 40.3 & $0.4(0.3$ to 0.5$)$ & $<0.0001$ \\
S2 & $28(20)$ & $110(10)$ & 10.3 & $2.0(1.3$ to 3.2$)$ & 0.0013 \\
S3D & $38(27)$ & $361(33)$ & 0.1 & $0.9(0.6$ to 1.3$)$ & 0.7060 \\
S3P & $61(43)$ & $313(28)$ & 9.6 & $1.6(1.2$ to 2.2$)$ & 0.0019 \\
X & $64(45)$ & $616(56)$ & 3.6 & $0.8(0.6$ to 1.0$)$ & 0.0571 \\
\hline
\end{tabular}

$\mathrm{RA}=$ rheumatoid arthritis. du Montcel classification is from du Montcel et al. [7]. *Data from Robinson and colleagues [31,32].

XX genotype used as a comparator. The low-risk genotype groups were (1) S1, consisting of genotypes $\mathrm{S} 1 / \mathrm{S} 1$ $+\mathrm{S} 1 / \mathrm{X}$; (2) S3D, consisting of S3D/S3D + S3D/X; and (3) $\mathrm{S} 1 / \mathrm{S} 3 \mathrm{D}$, consisting of $\mathrm{S} 1 / \mathrm{S} 1+\mathrm{S} 1 / \mathrm{X}+\mathrm{S} 3 \mathrm{D} / \mathrm{S} 3 \mathrm{D}+$ $\mathrm{S} 3 \mathrm{D} / \mathrm{X}+\mathrm{S} 1 / \mathrm{S} 3 \mathrm{D}$. The high-risk genotype groups were (1) S2, consisting of genotypes $\mathrm{S} 2 / \mathrm{S} 2+\mathrm{S} 2 / \mathrm{X}$; (2) S3P, consisting of S3P/S3P + S3P/X; and (3) S2/S3P, consisting of $\mathrm{S} 2 / \mathrm{S} 2+\mathrm{S} 2 / \mathrm{X}+\mathrm{S} 3 \mathrm{P} / \mathrm{S} 3 \mathrm{P}+\mathrm{S} 3 \mathrm{P} / \mathrm{X}+\mathrm{S} 2 / \mathrm{S} 3 \mathrm{P}$. As shown in Table 7 , these comparisons revealed a highly significant risk associated with the S2/S3P, S3P and S1/ S3D groups and, to a lesser extent, S1 and S3D as described in previous studies $[21,40]$. No predisposing effect associated with RF seropositivity was identified, which confirms that the SE alleles are primarily associated with aCCP.

Relationship of shared epitope with other circulating biomarkers and clinical markers of disease activity

Analysis (one-way ANOVA and Mann-Whitney $U$ test) of the median values of the other circulating biomarkers and clinical markers of disease activity revealed significant associations with CRP (SS vs SX vs XX: $P=$ 0.0041 ; SS vs SX: $P=0.0018$ ), SAA (SS vs SX vs XX: $P$ $=0.0018$; SS vs SX: $P=0.0005)$, TNF (SS vs SX vs XX: $P=0.0295)$, IL-1Ra (SS vs XX: $P=0.0311)$ and DAS28 (SS vs SX vs XX: $P=0.0324$; SS vs XX: $P=0.0103$; SX vs $\mathrm{XX}: P=0.0210)$. These trends were also noted with regard to most of the other cytokines, although they were not statistically significant (IL-1 3 , IL-2, IL-4, IL-6, IL-8, IL-12, CCL4, G-CSF, GM-GSF and IFN- $\gamma$ ).

Statistical comparison of the S1, S2, S3D and S3P groups did not reveal any significant differences, but in general the highest means for acute phase reactants, proinflammatory or anti-inflammatory cytokines, chemokines and VEGF were located predominantly in the SS-associated groups (data not shown).

\section{Discussion}

Relatively few studies have been undertaken to evaluate the occurrence of RA-associated HLA-DRB1 alleles in southern African people with RA. The results of the current study, on the basis of high-resolution typing procedures in combination with the du Montcel HLADRB1 SE classification system [7], reveal that the incidence of RA risk-associated alleles in a population of predominantly black South African females with RA is comparable to or higher than those reported in European and Japanese populations [19-21] and somewhat higher than those reported in the relatively few studies undertaken in African Americans, which range from $25 \%$ to $40 \%$ [35-37]. Our data are in agreement with those of an earlier study where low-resolution PCR typing procedures were used, in which HLA-DRB1*04 conferred the most significant risk of RA in a cohort of black South African RA patients [38]. According to the du Montcel classification system [7], the highest risk of RA is associated with the S2 and S3P alleles. Recently, Barnetche et al. [19] reported an association between RA susceptibility and HLA-DRB1 alleles (categorized according to the du Montcel classification system [7]) in a combined analysis of worldwide samples (1,210 cases of RA), which included 23 San people of southern African origin. Although the number of cases was small, $52.2 \%$ of the patients were found to be carriers of the S2 RA susceptibility allele compared to $26 \%$ in the control group $(O R=3.05)$ [19]. In addition, in agreement with

Table 5 Relationship between human leucocyte antigen-DRB1 shared epitope homozygosity or heterozygosity and risk of anticyclic citrullinated peptide antibody or rheumatoid factor seropositivity

\begin{tabular}{|c|c|c|c|c|c|c|c|c|}
\hline & \multicolumn{4}{|c|}{ Total cohort $(n=143)$} & \multicolumn{4}{|c|}{ Blacks $(n=124)$} \\
\hline & \multicolumn{2}{|c|}{ SS $(n=80)$} & \multicolumn{2}{|c|}{ SX $(n=52)$} & \multicolumn{2}{|c|}{ SS $(n=72)$} & \multicolumn{2}{|c|}{$S X(n=43)$} \\
\hline & OR $(95 \% \mathrm{Cl})$ & $P$ value & OR $(95 \% \mathrm{Cl})$ & $P$ value & OR $(95 \% \mathrm{Cl})$ & $P$ value & OR $(95 \% \mathrm{Cl})$ & $P$ value \\
\hline$\overline{\mathrm{RF}}$ & 7.0 (1.8 to 26.6$)$ & 0.0059 & 6.3 (1.5 to 25.7$)$ & 0.0126 & 4.5 (1.0 to 19.5$)$ & 0.0537 & 4.1 (0.9 to 19.3) & 0.0813 \\
\hline $\mathrm{aCCP}$ & $10.2(2.6$ to 40.3$)$ & 0.0010 & $9.2(2.2$ to 38.9$)$ & 0.0028 & 7.1 (1.6 to 30.4$)$ & 0.0121 & $6.4(1.4$ to 30.1$)$ & 0.0223 \\
\hline
\end{tabular}

$\mathrm{aCCP}=$ anticyclic citrullinated peptide antibodies; HLA = human leucocyte antigen; RF = rheumatoid factor; $\mathrm{SE}=$ shared epitope; $\mathrm{SS}=$ homozygous for shared epitope allele; $\mathrm{SX}=$ heterozygous for shared epitope allele. 
Table 6 Association between anticyclic citrullinated peptide antibody and rheumatoid factor with shared epitope alleles according to the du Montcel classification

\begin{tabular}{|c|c|c|c|c|}
\hline \multirow[b]{2}{*}{ Allele } & \multicolumn{2}{|l|}{$\mathrm{aCCP}$} & \multicolumn{2}{|l|}{$\mathrm{RF}$} \\
\hline & OR $(95 \% \mathrm{Cl})$ & $P$ value & OR $(95 \% \mathrm{Cl})$ & $\begin{array}{c}P \\
\text { value }\end{array}$ \\
\hline 51 allele $(n=55)$ & $2.9(0.7$ to 12.4$)$ & 0.2054 & $\begin{array}{c}4.5(1.2 \text { to } \\
16.9)\end{array}$ & ${ }^{*} 0.0291$ \\
\hline S2 allele $(n=28)$ & $\begin{array}{c}12.0(2.4 \text { to } \\
59.5)\end{array}$ & $0.0019^{* *}$ & $\begin{array}{c}8.3(1.6 \text { to } \\
43.3)\end{array}$ & $*^{*} 0.0122$ \\
\hline $\begin{array}{l}\text { S3D allele }(n= \\
38)\end{array}$ & 7.5 (1.8 to 31.4$)$ & $0.0100^{*}$ & $\begin{array}{l}5.3(1.3 \text { to } \\
22.7)\end{array}$ & ${ }^{*} 0.0246$ \\
\hline S3P allele $(n=61)$ & $\begin{array}{c}13.3(3.2 \text { to } \\
54.4)\end{array}$ & $0.0003^{* * *}$ & $\begin{array}{c}4.5(1.2 \text { to } \\
16.8)\end{array}$ & ${ }^{*} 0.0264$ \\
\hline $\mathrm{X}$ allele $(n=64)$ & 4.7 (1.2 to 17.6$)$ & $0.0213^{*}$ & 2.7 (0.8 to 9.8 ) & 0.1678 \\
\hline
\end{tabular}

$\mathrm{aCCP}=$ anticyclic citrullinated peptide antibodies; RF = rheumatoid factor. $\mathrm{du}$ Montcel classification is from du Montcel et al. [7]. OR $(95 \% \mathrm{Cl})$ and $P$ values were calculated using Fisher's exact test to compare with SE noncarrier rheumatoid arthritis patients $(n=12)$. ${ }^{*} P<0.05$. ${ }^{* *} P \leq 0.001$ and ${ }^{* * *} P \leq 0.0003$ values are highly significant.

previous European and Japanese RA cohort studies $[19,40]$, we observed highly significant associations of SS and SX with seropositivity for aCCP but not RF $[21,40]$. We have previously reported that isolated measurement of aCCP is no more accurate than RF in the serodiagnosis of RA [41]. However, when used in combination with SE genotyping, measurement of aCCP appears to distinguish a subset of patients who may differ with respect to response to therapy and outcome.

These observations appear to support the relationship between HLA-DRB1 SE subtypes, presentation of citrullinated epitopes and development of RA [42]. This contention is underscored by the broad associations of circulating cytokines with the du Montcel classification system risk phenotype [7]. SS is most strongly associated with T-helper cell 1 (GM-CSF, TNF, IFN- $\gamma$ and IL-2),

Table 7 Predisposing effect of shared epitope genotypes on anticyclic citrullinated peptide antibody and rheumatoid factor seropositivity

\begin{tabular}{lcccc}
\hline & \multicolumn{2}{c}{ aCCP } & \multicolumn{2}{c}{ RF } \\
\cline { 2 - 5 } SE groups & OR $(\mathbf{9 5 \%}$ Cl) & $\boldsymbol{P}$ value & OR $(\mathbf{9 5 \%}$ Cl) & $\boldsymbol{P}$ value \\
\hline S1 $(n=24)$ & $2.4(1.1$ to 5.4$)$ & $0.0113^{*}$ & $1.6(0.9$ to 2.9$)$ & 0.1245 \\
S3D $(n=17)$ & $2.3(1.0$ to 5.4$)$ & $0.0287^{*}$ & $1.7(0.9$ to 3.0$)$ & 0.1059 \\
S1/S3D $(n=50)$ & $2.3(1.0$ to 5.3$)$ & $0.0049^{* *}$ & $1.6(0.9$ to 2.9$)$ & 0.0611 \\
S2 $(n=11)$ & $2.2(0.9$ to 5.2$)$ & 0.0995 & $1.6(0.9$ to 3.1$)$ & 0.1930 \\
S3P $(n=28)$ & $2.5(1.1$ to 5.6$)$ & $0.0075^{* *}$ & $1.6(0.9$ to 3.0$)$ & 0.0563 \\
S2/S3P $(n=47)$ & $2.4(1.1$ to 5.5$)$ & $0.0025^{* *}$ & $1.6(0.9$ to 2.8$)$ & 0.0687
\end{tabular}

$\mathrm{aCCP}=$ anticyclic citrullinated peptide antibodies; RF = rheumatoid factor; SE = shared epitope. OR $(95 \% \mathrm{Cl})$ and $P$ values were calculated using Fisher's exact test to compare rheumatoid arthritis patients with RA patients with the $X / X$ genotype $(n=12) .{ }^{*} P<0.05$. ${ }^{* *} P \leq 0.008$ values are highly significant. Groups S1, S3D, S2 and S3P consisted of the pooled homozygotes (SS) and heterozygotes (SX) for each group. Group S1/S3D consisted of S1/S1, S1/X, S3D/S3D, S3D/X and S1/S3D. Group S2/S3P consisted of S2/S2, S2/X, S3P/S3P, $\mathrm{S} 3 \mathrm{P} / \mathrm{X}$ and S2/S3P.
Th2 (IL-4 and IL-6) and macrophage (IL-1 $\beta$, IL-6, IL-8, IL-12, TNF and VEGF) cytokines, as well as with IL$1 \mathrm{Ra}$. We and others have previously reported that RA is associated with a generalised increase in circulating proinflammatory and anti-inflammatory cytokines and chemokines, which might be compatible with Th1, macrophage and fibroblast activation and a counterregulatory role of Th2 cells $[22,23,43]$.

Our findings are somewhat at variance with those recently reported by Singwe-Ngandeu et al. [44] in a relatively small group of Cameroonian RA patients $(n=$ 56). Thirty percent of the RA patients in their study were either SS or SX compared to $10 \%$ in patients with other inflammatory rheumatic diseases and $14 \%$ in healthy controls. However, no significant associations between SE positivity (SS or SX) and aCCP or RF were detected. Several possible reasons might explain the differences between their study and our present study. Notwithstanding the relatively small number of patients, these differences include the number of alleles typed (21 in Singwe-Ngandeu et al. vs 43 in our present study) and, most importantly, the effects of chemotherapy. Whereas the patients in our study were corticosteroidand DMARD-naïve at the time of presentation, the patients in the Singwe-Ngandeu et al. study were receiving prednisone (91\%), methotrexate (77\%), sulfasalazine (12\%), azathioprine (5\%), leflunomide (5\%) and D-penicillamine (2\%). Although this difference may explain the absence of associations of SE alleles with aCCP and RF, it is unlikely to explain the differences in frequencies of SE alleles detected in the two studies. Notwithstanding the larger number of alleles typed in the current study, it is also possible that our patients represent those at the extreme end of the severe disease spectrum. In the health care setting of the developing world, the presentation of patients to specialised RA clinics, of which there are few, is likely to be delayed, and our study cohort may therefore reflect a selection bias of patients seen in a tertiary setting.

\section{Conclusions}

The results of the current study demonstrate an increased frequency of high-risk SE alleles in a predominantly black South African population with RA. We have also shown a clear association of high-risk SE alleles with aCCP in particular, to a lesser extent with $\mathrm{RF}$, with circulating cytokines and chemokines and possibly with disease severity.

\section{Abbreviations}

aCCP: anticyclic citrullinated peptide antibodies; CRP: C-reactive protein; DAS28: Disease Activity Score in 28 joints; DMARD: disease-modifying antirheumatic drug; HLA: human leucocyte antigen; IFN: interferon; IL: interleukin; $\mathrm{mAb}=$ monoclonal antibody; PCR: polymerase chain reaction; 
RA: rheumatoid arthritis; RF: rheumatoid factor; SE: shared epitope; SS: homozygous for shared epitope allele; SX: heterozygous for shared epitope allele; Th: T helper cell; TNF: tumour necrosis factor; XX: no shared epitope allele.

\section{Acknowledgements}

We thank the Connective Tissue Diseases Research Fund, University of the Witwatersrand. We thank The Terasaki Foundation for supplying the reverse sequence-specific oligonucleotide HLA-DRB1 kits.

\section{Author details}

${ }^{1}$ Medical Research Council Unit for Inflammation and Immunity, Department of Immunology, Faculty of Health Sciences, University of Pretoria, and Tshwane Academic Division of the National Health Laboratory Service, Bophelo Road, Pretoria, 0001, South Africa. Division of Rheumatology, Chris Hani Baragwanath Hospital, Faculty of Health Sciences, University of the Witwatersrand, Chris Hani Road, Johannesburg, 2013, South Africa. ${ }^{3}$ Department Internal Medicine, Faculty of Health Sciences, University of Pretoria, Bophelo Road, Pretoria, 0001, South Africa. ${ }^{4}$ Epidemiology and Biostatistics Division, School of Public Health, Faculty of Health Sciences, University of the Witwatersrand, York Road, Johannesburg, 2193, South Africa. ${ }^{5}$ Department of Immunology, School of Pathology, University of the Witwatersrand and the National Health Laboratory Service, Hospital Street, Braamfontein, 2001, Johannesburg, South Africa.

\section{Authors' contributions}

PWAM was responsible for the study design and the generation, analysis and communication of data. $\mathrm{BH}$ and MA were responsible for the study design, clinical assessment, and analysis and communication of data. EM was responsible for the statistical design and data analysis. AAW was responsible for the study design and communication of data. HF performed laboratory investigations and data analysis. MT was responsible for the study design, served as the clinical coordinator, and performed data analysis and communication. RA was responsible for the study design and the analysis and communication of data. All authors read and approved the final manuscript.

\section{Competing interests}

The authors declare that they have no competing interests.

Received: 2 March 2011 Revised: 2 March 2011

Accepted: 6 October 2011 Published: 6 October 2011

\section{References}

1. Pratt AG, Isaacs JD, Mattey DL: Current concepts in the pathogenesis of early rheumatoid arthritis. Best Pract Res Clin Rheumatol 2009, 23:37-48.

2. Nepom GT, Seyfried CE, Holbeck SL, Wilske KR, Nepom BS: Identification of HLA-Dw14 genes in DR4+ rheumatoid arthritis. Lancet 1986, 2:1002-1005.

3. Winchester R: Genetic determination of susceptibility and severity in rheumatoid arthritis. Ann Intern Med 1992, 117:869-871.

4. Winchester R: The molecular basis of susceptibility to rheumatoid arthritis. Adv Immunol 1994, 56:389-466

5. Gregersen PK, Silver J, Winchester RJ: The shared epitope hypothesis: an approach to understanding the molecular genetics of susceptibility to rheumatoid arthritis. Arthritis Rheum 1987, 30:1205-1213.

6. Gao XJ, Brautbar C, Gazit E, Segal R, Naparstek Y, Livneh A, Stastny P: A variant of HLA-DR4 determines susceptibility to rheumatoid arthritis in a subset of Israeli Jews. Arthritis Rheum 1991, 34:547-551.

7. du Montcel ST, Michou L, Petit-Teixeira E, Osorio J, Lemaire I, Lasbleiz S, Pierlot C, Quillet P, Bardin T, Prum B, Cornelis F, Clerget-Darpoux F: New classification of HLA-DRB1 alleles supports the shared epitope hypothesis of rheumatoid arthritis susceptibility. Arthritis Rheum 2005, 52:1063-1068

8. Michou L, Croiseau P, Petit-Teixeira E, du Montcel ST, Lemaire I, Pierlot C, Osorio J, Frigui W, Lasbleiz S, Quillet P, Bardin T, Prum B, Clerget-Darpoux F, Cornélis F, European Consortium on Rheumatoid Arthritis Families: Validation of the reshaped shared epitope HLA-DRB1 classification in rheumatoid arthritis. Arthritis Res Ther 2006, 8:R79.

9. Schellekens GA, de Jong BA, van den Hoogen $F H$, van de Putte $L B$, van Venrooij WJ: Citrulline is an essential constituent of antigenic determinants recognized by rheumatoid arthritis-specific autoantibodies. J Clin Invest 1998, 101:273-281.

10. Mattey DL, Hassell AB, Plant MJ, Cheung NT, Dawes PT, Jones PW, Thomson W, Poulton KV, Hajeer AH, Ollier WE: The influence of HLA-DRB1 alleles encoding the DERAA amino acid motif on radiological outcome in rheumatoid arthritis. Rheumatology (Oxford) 1999, 38:1221-1227.

11. van Boekel MA, Vossenaar ER, van den Hoogen FH, van Venrooij WJ: Autoantibody systems in rheumatoid arthritis: specificity, sensitivity and diagnostic value. Arthritis Res 2002, 4:87-93.

12. Hill JA, Southwood S, Sette A, Jevnikar AM, Bell DA, Cairns E: Cutting edge: the conversion of arginine to citrulline allows for a high-affinity peptide interaction with the rheumatoid arthritis-associated HLA-DRB1*0401 MHC class II molecule. J Immunol 2003, 171:538-541.

13. Auger I, Sebbag M, Vincent C, Balandraud N, Guis S, Nogueira L, Svensson B, Cantagrel A, Serre G, Roudier J: Influence of HLA-DR genes on the production of rheumatoid arthritis-specific autoantibodies to citrullinated fibrinogen. Arthritis Rheum 2005, 52:3424-3432.

14. Huizinga TW, Amos Cl, van der Helm-van Mil AH, Chen W, van Gaalen FA, Jawaheer D, Schreuder GM, Wener M, Breedveld FC, Ahmad N, Lum RF, de Vries RR, Gregersen PK, Toes RE, Criswell LA: Refining the complex rheumatoid arthritis phenotype based on specificity of the HLA-DRB1 shared epitope for antibodies to citrullinated proteins. Arthritis Rheum 2005, 52:3433-3438.

15. Raza K, Breese M, Nightingale P, Kumar K, Potter T, Carruthers DM, Situnayake D, Gordon C, Buckley CD, Salmon M, Kitas GD: Predictive value of antibodies to cyclic citrullinated peptide in patients with very early inflammatory arthritis. J Rheumatol 2005, 32:231-238.

16. Samanci N, Ozdem S, Akbas H, Mutlu D, Gultekin M, Arman M, Donmez L: Diagnostic value and clinical significance of anti-CCP in patients with advanced rheumatoid arthritis. J Natl Med Assoc 2005, 97:1120-1126.

17. de Vries RRP, Huizinga TWJ, Toes REM: HLA and RA revisited: citrullinated food for the SE hypothesis, the DR6 effect, and NIMA. Hum Immunol 2006, 67:454-459.

18. Quinn MA, Gough AKS, Green MJ, Devlin J, Hensor EMA, Greenstein A Fraser A, Emery P: Anti-CCP antibodies measured at disease onset help identify seronegative rheumatoid arthritis and predict radiological and functional outcome. Rheumatology (Oxford) 2006, 45:478-480.

19. Barnetche T, Constantin A, Cantagrel A, Cambon-Thomsen A, Gourraud P: New classification of HLA-DRB1 alleles in rheumatoid arthritis susceptibility: a combined analysis of worldwide samples. Arthritis Res Ther 2008, 10:R26.

20. Okada Y, Yamada R, Suzuki A, Kochi Y, Shimane K, Myouzen K, Kubo M, Nakamura $Y$, Yamamoto $K$ : Contribution of a haplotype in the HLA region to anti-cyclic citrullinated peptide antibody positivity in rheumatoid arthritis, independently of HLA-DRB1. Arthritis Rheum 2009, 60:3582-3590.

21. Gyetvai A, Szekanecz Z, Soos L, Szabo Z, Fekete A, Kapitany A, Teodorescu M, Sipka S, Szegedi G, Lakos G: New classification of the shared epitope in rheumatoid arthritis: impact on the production of various anti-citrullinated protein antibodies. Rheumatology (Oxford) 2010, 49:25-33.

22. Kokkonen H, Söderström I, Rocklöv J, Hallmans G, Lejon K, Rantapää Dahlqvist S: Up-regulation of cytokines and chemokines predates the onset of rheumatoid arthritis. Arthritis Rheum 2010, 62:383-391.

23. Deane KD, O'Donnell Cl, Hueber W, Majka DS, Lazar AA, Derber LA, Gilliland WR, Edison JD, Norris JM, Robinson WH, Holers VM: The number of elevated cytokines and chemokines in preclinical seropositive rheumatoid arthritis predicts time to diagnosis in an age-dependent manner. Arthritis Rheum 2010, 62:3161-3172

24. Hitchon CA, Alex P, Erdile LB, Frank MB, Dozmorov I, Tang Y, Wong K, Centola M, El-Gabalawy HS: A distinct multicytokine profile is associated with anti-cyclical citrullinated peptide antibodies in patients with early untreated inflammatory arthritis. J Rheumatol 2004, 31:2336-2346.

25. Alex P, Szodoray P, Knowlton N, Dozmorov IM, Turner M, Frank MB, Arthur RE, Willis L, Flinn D, Hynd RF, Carson C, Kumar A, El-Gabalawy HS, Centola M: Multiplex serum cytokine monitoring as a prognostic tool in rheumatoid arthritis. Clin Exp Rheumatol 2007, 25:584-592.

26. Chen DY, Hsieh TY, Chen YM, Hsieh CW, Lan JL, Lin FJ: Proinflammatory cytokine profiles of patients with elderly-onset rheumatoid arthritis: a comparison with younger-onset disease. Gerontology 2009, 55:250-258.

27. Boissier MC: Cell and cytokine imbalances in rheumatoid synovitis. Joint Bone Spine 2011, 78:230-234. 
28. Arnett FC, Edworthy SM, Bloch DA, McShane DJ, Fries JF, Cooper NS, Healey LA, Kaplan SR, Liang MH, Luthra HS, Medsger TA Jr, Mitchell DM, Neustadt DH, Pinals RS, Schaller JG, Sharp JT, Wilder RL, Hunder GG: The American Rheumatism Association 1987 revised criteria for the classification of rheumatoid arthritis. Arthritis Rheum 1988, 31:315-324.

29. Inoue $\mathrm{E}$, Yamanaka H, Hara M, Tomatsu T, Kamatani N: Comparison of Disease Activity Score (DAS)28- erythrocyte sedimentation rate and DAS28- C-reactive protein threshold values. Ann Rheum Dis 2007, 66:407-409.

30. Wells GA: Patient-driven outcomes in rheumatoid arthritis. J Rheumatol 2009, 36:33-38.

31. Robinson J, Waller MJ, Parham P, De Groot N, Bontrop R, Kennedy $L$, Stoehr P, Marsh SGE: IMGT/HLA and IMGT/MHC: sequence databases for the study of the major histocompatibility complex. Nucleic Acids Res 2003, 31:311-314.

32. Robinson J, Waller MJ, Fail SC, McWilliam H, Lopez R, Parham P, Marsh SGE: The IMGT/HLA database. Nucleic Acids Res 2009, 37:D1013-D1017.

33. Middleton $D$, Menchaca $L$, Rood $H$, Komerofsky R: New allele frequency database. Tissue Antigens 2003, 61:403-407[http://www.allelefrequencies. net].

34. Mbayo K, Mbuyi-Muamba JM, Hallé L, Salmon D, Martageix C, Castellano F, Kaplan C, Lurhuma Z: HLA-DR gene frequencies in a Zairean population with particular reference to rheumatic diseases. Clin Rheumatol 1998, 17:105-109.

35. Del Rincón I, Battafarano DF, Arroyo RA, Murphy FT, Fisbach M, Escalante A: Ethnic variation in the clinical manifestations of rheumatoid arthritis: role of HLA-DRB1 alleles. Arthritis Care Res 2003, 49:200-208.

36. Hughes LB, Morrison D, Kelley JM, Padilla MA, Vaughan LK, Westfall OA, Dwivedi H, Mikuls TR, Holers VM, Parrish LA, Alarcón GS, Jonas BL, Callahan LF, Smith EA, Gilkeson GS, Howard G, Moreland LW, Patterson N, Reich D, Bridges SL Jr: The HLA-DRB1 shared epitope is associated with susceptibility to rheumatoid arthritis in African Americans through European genetic admixture. Arthritis Rheum 2008, 58:349-358.

37. Mikuls TR, Sayles H, Yu F, Levan T, Gould KA, Thiele GM, Conn DL, Jonas BL, Callahan LF, Smith E, Brasington R, Moreland LW, Reynolds RJ, Bridges SL Jr: Associations of cigarette smoking with rheumatoid arthritis in African Americans. Arthritis Rheum 2010, 62:3560-3568.

38. Meyer PWA, Brighton SW, Anderson R: Association of the HLA-DRB1*04 allele and its subtypes with rheumatoid arthritis in South Africa. $S$ Afr $J$ Sci 2004, 100:305-306.

39. Klareskog L, Rönnelid J, Lundberg K, Padyukov L, Alfredsson L: Immunity to citrullinated proteins in rheumatoid arthritis. Ann Rev Immunol 2008, 26:206-209.

40. Engelmann R, Eggert M, Neeck G, Mueller-Hilke B: The impact of HLA-DRB alleles on the subclass titres of antibodies against citrullinated peptides. Rheumatology (Oxford) 2010, 49:1862-1866.

41. Hodkinson B, Meyer PW, Musenge E, Ally MM, Wadee AA, Anderson B, Tikly M: The diagnostic utility of the anti-CCP antibody test is no better than rheumatoid factor in South Africans with early rheumatoid arthritis. Clin Rheumatol 2010, 29:615-618.

42. Szodoray P, Szabó Z, Kapitány A, Gyetvai A, Lakos G, Szántó S, Szücs G, Szekanecz Z: Anti-citrullinated protein/peptide autoantibodies in association with genetic and environmental factors as indicators of disease outcome in rheumatoid arthritis. Autoimmun Rev 2010, 9:140-143.

43. Meyer PWA, Hodkinson B, Mahmood A, Musenge E, Wadee AA, Fickl H, Tikly M, Anderson R: Circulating cytokine profiles and their relationship with autoantibodies, acute phase reactants, and disease activity in patients with rheumatoid arthritis. Mediators Inflamm 2010, 2010:158154

44. Singwe-Ngandeu M, Finckh A, Bas S, Tiercy JM, Gabay C: Diagnostic value of anti-cyclic citrullinated peptides and association with HLA-DRB1 shared epitope alleles in African rheumatoid arthritis patients. Arthritis Res Ther 2010, 12:R36.

doi:10.1186/ar3479

Cite this article as: Meyer et al:: HLA-DRB1 shared epitope genotyping using the revised classification and its association with circulating autoantibodies, acute phase reactants, cytokines and clinical indices of disease activity in a cohort of South African rheumatoid arthritis patients. Arthritis Research \& Therapy 2011 13:R160.

\section{Submit your next manuscript to BioMed Central and take full advantage of:}

- Convenient online submission

- Thorough peer review

- No space constraints or color figure charges

- Immediate publication on acceptance

- Inclusion in PubMed, CAS, Scopus and Google Scholar

- Research which is freely available for redistribution

Submit your manuscript at www.biomedcentral.com/submit 